\title{
Aims, methods and preliminary findings of the Physical Activity, Nutrition and Allergies in Children Examined in Athens (PANACEA) epidemiological study
}

\author{
Kostas N Priftis ${ }^{1}$, Demosthenes B Panagiotakos*2, \\ Michael B Anthracopoulos ${ }^{3}$, Anastasios Papadimitriou ${ }^{4}$ and \\ Polyxeni Nicolaidou ${ }^{4}$
}

Address: ${ }^{1}$ Department of Allergy-Pneumonology, Penteli Children's Hospital, P. Penteli, Greece, ${ }^{2}$ Department of Nutrition Science - Dietetics, Harokopio University, Athens, Greece, ${ }^{3}$ Respiratory Unit, Department of Pediatrics, School of Medicine, University of Patras, Rio, Greece and ${ }^{4}$ Third Department of Pediatrics, Attikon Hospital, School of Medicine, University of Athens, Athens, Greece

Email: Kostas N Priftis - kpriftis@otenet.gr; Demosthenes B Panagiotakos* - d.b.panagiotakos@usa.net;

Michael B Anthracopoulos - manthra@otenet.gr; Anastasios Papadimitriou - lix@ath.forthnet.gr; Polyxeni Nicolaidou - pedatt@med.uoa.gr

* Corresponding author

Published: 4 July 2007

BMC Public Health 2007, 7:140 doi:10.1 I86/147|-2458-7-140

This article is available from: http://www.biomedcentral.com/I47I-2458/7//40

(C) 2007 Priftis et al; licensee BioMed Central Ltd.

This is an Open Access article distributed under the terms of the Creative Commons Attribution License (http://creativecommons.org/licenses/by/2.0), which permits unrestricted use, distribution, and reproduction in any medium, provided the original work is properly cited.
Received: 2I March 2007

Accepted: 4 July 2007

\begin{abstract}
Background: To determine the prevalence of asthma symptoms in a sample of Greek children aged 10-12 years, and to evaluate these rates in relation to anthropometric, lifestyle characteristics and dietary habits.

Methods: During 2006, 700 schoolchildren (323 male and 377 female), aged 10-12 years (4th to $6^{\text {th }}$ school grade), were selected from 18 schools located in the greater Athens area. The schools were randomly selected from a list provided by the regional educational offices. To achieve a representative sample the schools enrolled were selected from various region of the Athens area. For each child a questionnaire was completed that was developed for the purposes of the study to retrieve information on: age, sex, school class, other socio-demographic characteristics, anthropometric measurements, dietary habits (through a semi-quantitative Food Frequency Questionnaire) and physical activity status; the presence of asthma and allergies was assessed by the standard ISAAC questionnaire.

Results: The prevalence of wheezing in the past was $25 \%$ in boys and $19 \%$ in girls, while the prevalence of current wheezing was $9.0 \%$ in boys and $5.8 \%$ in girls. The prevalence of any asthma symptoms was $27.6 \%$ in boys and $20.4 \%$ in girls. Multiple logistic regression analysis revealed that increased body weight and sedentary lifestyle is associated with asthma symptoms only in boys.

Conclusion: The present cross-sectional study cannot establish causal relationships between asthma and increased body weight of schoolchildren; however, our findings underline the associations between asthma, increased body weight, and physical activity at population level, and urge for actions that should be taken by public health policy makers in order to prevent these conditions among children.
\end{abstract}




\section{Background}

Asthma is the leading chronic childhood illness throughout the developed world and places a large burden on affected children and their families. Estimates of current asthma prevalence in the USA indicate that 83 per 1000 (i.e. 6.1 million) children aged 0-17 currently have asthma [1]. In Europe the prevalence of asthma is similar to that observed in the US and has increased decades earlier in Western as compared to Eastern Europe. The International Study of Asthma and Allergies in Childhood (ISAAC) [2] evaluated children 13-14 years-of-age from 56 countries and 6-7 years-of-age from 38 countries. The prevalence of wheezing ranged $4.1-32.1 \%$ in the younger age group and $2.1-32.2 \%$ in the older age group and was particularly high in English speaking countries and in Latin America. The major differences between populations found in the ISAAC study are most likely due to environmental factors. Many reports underline the importance of monitoring asthma prevalence, health care, and mortality in order to estimate the burden of the disease and to help assess the impact of asthma prevention programs and improvements in health care quality [3-5].

Parallel to the increase of asthma prevalence in children, there is a growing global childhood "obesity epidemic" with a large variation in secular trends across countries [6]. The most significant long-term consequence of childhood obesity is its persistence into adulthood, with all the attendant health risks. The likelihood of such persistence increases with the onset of obesity in late childhood or adolescence and with the severity of obesity [7]. Although the mechanisms responsible for the development of obesity are not fully understood, it has been confirmed that obesity occurs when energy intake exceeds energy expenditure; thus, dietary habits, physical activity, other lifestyle choices and cultural environment as well as a variety of genetic factors significantly influence its development [8].

The association between childhood asthma and body weight has been a matter of particular interest in recent literature and an increasing body of evidence implicates obesity as a major risk factor for asthma, thus linking these two epidemics [9-11]. Indeed, obese children may be prone to receive a diagnosis of asthma as they may complain of shortness of breath on physical exertion sooner than their non-obese peers [12] or they may actually experience increased exercise-induced broncho-constriction as compared to non-obese children [13]. Emerging evidence suggests that asthma symptoms and obesity in children show similar trends in the last few decades $[14,15]$ and that there is greater burden of respiratory symptoms and use of medication among obese children [16-18]. Overweight asthmatic children experience greater limitation of physical activity, while insufficient physical activity increases the risk for higher body mass index, thus perpetuating the vicious cycle of asthma, exercise-induced broncho-constriction, decreased physical activity and increased body weight.

A direct relationship between the prevalence of asthma symptoms, rhinitis and eczema, and dietary factors has been observed [19]; a higher total polyunsaturated fat intake in young sensitized wheezy children has also been reported [20]. There is increasing interest in recent literature with regard to the importance of dietary antioxidant and lipid intake in the expression of asthma during pregnancy and early childhood [21].

In Greece a greater than 4-fold increase in the prevalence of childhood asthma and wheezing has occurred over the last 25 years [22]. A high prevalence of overweight and obesity and a concomitant positive secular change over the last decades has also been observed [23,24], and associated by some investigators with increases in asthma prevalence. Therefore, the Physical Activity, Nutrition and Allergies in Children Examined in Athens (PANACEA) study was designed to determine the prevalence of asthma symptoms among Greek schoolchildren and to evaluate these rates in relation to anthropometric, lifestyle characteristics and dietary habits of the children. This report illustrates the PANACEA study aims, design and methods used, as well as the associations between asthma symptoms and dietary and physical activity characteristics of the participants.

\section{Methods}

The PANACEA study is an epidemiological cross-sectional survey that has three main research hypotheses, i.e. that the prevalence of asthma and allergies in 10-12 year-old boys and girls from Greece is related to their: (a) sociodemographic characteristics, (b) level of physical activity, and (c) dietary habits. Further, it will investigate the interactions between diet, physical activity and socio-demographic characteristics, in relation to the prevalence of asthma and allergic symptoms.

The study has been designed according to the principles of the declaration of Helsinki (1989). The protocol of the study has been approved by the Education Institute of the Hellenic Ministry of Education (approval 29712/G7/ 2006). All participants were interviewed and evaluated by trained personnel (pediatricians, general practitioners, dieticians and nurses) who used a standard questionnaire with closed-ended questions.

\section{Study sample}

During 2006, 815 schoolchildren aged $10-12$ (4th to $6^{\text {th }}$ school grade) years from 18 public schools located in the greater Athens area were recruited to participate in the study. Seven hundred schoolchildren (323 male and 377 
female) agreed to enrol into the Study (participation rate $83.5 \%$ ). The schools were randomly selected from a list of schools provided by the regional education offices. In order to achieve a representative sample the enrolled schools were selected from various regions of Athens.

Participation of subjects was on a voluntary basis; prior to acceptance, children's guardians were fully informed on the objectives and methods of the study and signed an informed consent. Only pre-menstrual girls were included. Children suffering from chronic diseases that prohibited free running, i.e. cyanotic heart disease or severe motor handicaps, were also excluded.

The number of enrolled children was adequate (i.e., statistical power $>85 \%$ ) to evaluate two-sided hypotheses regarding standardized differences between various balanced groups (such as obese $v$ s. non-obese children, physically active vs. inactive etc.) greater than 0.5 at the probability level of $<0.05$.

\section{Funding}

The study was funded by research grants by the Respiratory Unit of the Department of Pediatrics, University of Patras, Greece.

\section{Socio-demographic and anthropometric measurements}

The parents of every child completed a questionnaire that was developed for the purposes of the study and was designed to retrieve information on: age (in years), sex, school class (i.e., $4^{\text {th }}, 5^{\text {th }}$ or $6^{\text {th }}$ ), dietary habits, asthma and other allergic symptoms. The same questionnaire also included information regarding the social status of the family, i.e. educational level of the parents (none, basic education, high school, academic), number of cars within the family, availability of child's own-room and number of siblings as well as information on hospitalizations of the children. A special questionnaire on the children's physical activity was completed at school by children themselves.

Standing height was measured with a Raven Minimeter (Raven Equipment Limited, Essex, United Kingdom) to the nearest $0.1 \mathrm{~cm}$ and body weight to the nearest $0.1 \mathrm{~kg}$ with a Seca weighing scale (Seca, Hanover, MD) after students had removed their clothes and shoes. Measurements took place at the school setting. Overweight and obesity were defined using the international body mass index cut-off points established for children and youth [25]. These cut-off points are based on health-related adult definitions of overweight $\left(25-29.9 \mathrm{~kg} / \mathrm{m}^{2}\right)$ and obesity $\left(\geq 30 \mathrm{~kg} / \mathrm{m}^{2}\right)$, and are adjusted to specific age and sex categories for children. Parents were also asked to report the height and weight of their children.
Children's birth-weight was reported by the parents who were encouraged to use the standard health record booklet that accompanies each child in Greece from birth; the information was entered into the following five categories: $<1,500 \mathrm{~g}, 1500-2,000 \mathrm{~g}, 2,000-2,500 \mathrm{~g}, 2,500-3,500$ $\mathrm{g}$ and $>3,500 \mathrm{~g}$. Information on breast-feeding and its duration (in months) was also provided.

Reported height, weight and calculated BMI of both parents were recorded. Parents were classified as normal, overweight (BMI: $25.0-29.9 \mathrm{~kg} / \mathrm{m}^{2}$ ) or obese (BMI: $\geq 30.0$ $\left.\mathrm{kg} / \mathrm{m}^{2}\right)$.

\section{Evaluation of asthma symptoms}

In order to evaluate asthma symptoms, the approved Greek version of the International Study for Asthma and Allergies in Childhood (ISAAC) core questionnaire was employed $[2,26]$. In particular, the evaluation of presence and duration of asthma symptoms was assessed by four questions according to ISAAC classification: 1) if children ever had wheezing, 2) if they ever had disturbed sleep due to wheezing, 3) if they ever had asthma, and 4) if they ever had dry cough at night, except in case of cold or chest infection [2].

\section{Evaluation of dietary habits}

A semi-quantitative Food Frequency Questionnaire (FFQ) that gathers information on a daily and weekly basis was applied to all children. Various foods and beverages commonly consumed in Greece, and habits pertaining to mealtime behaviours were recorded by using 63 detailed descriptive questions. In particular, we measured the weekly or daily intake of dairy products with breakfast, the frequency of breakfast consumption, the frequency of consumption of cereals with breakfast, the daily consumption of meals including snacks, the frequency of consumption of foods outside the home (including school canteens and non home-made meals), the cooking method usually employed by the family, the type of oils/ fat consumed, the frequency of snacks consumed and the frequency of consumption of various foods such as: fish, poultry, red meat, eggs, white bread, whole grain bread, potatoes, rice, fruits, vegetables, fruit juices, soda drinks, low-calorie soft drinks, beverages, and of traditional Greek cooked meals. The above mentioned foods and beverages were categorized as follows: (1) "dairy products" that included all kinds of milk, yoghurt and cheese; (2) snacks were categorized into two main types: "salty" snacks (such as hamburger, pizza, hot-dog, toast, cheese pie, spinach pie, all kind of crisps, popcorn) and "sweet" snacks (such as ice-cream, milk shake, all kinds of chocolate, croissant, cakes, biscuits); (3) any type of soda drink; (4) fruit juices (fresh, or ready-made); (5) other beverages (such as tea, chamomile, etc); and (6) traditional Greek cooked foods. Typical serving sizes were employed as 
units for measurements and for every food/drink item in the questionnaire, a clearly described measure was used (e.g. a can of soft drink, one hamburger, one portion of chicken approximately $150 \mathrm{gr}$, a bag of crisps, etc). When the FFQ was completed, subjects indicated the average frequency of consumption of the reported amount of each food item. Furthermore, based on the above questionnaire, the daily energy intake of every child was calculated (in kcal). Then all children were categorized into four groups: (a) low ( $<1,800 \mathrm{kcal})$, (b) moderate $(1,800-2000$ $\mathrm{kcal})$, (c) adequate $(2,000-2,350 \mathrm{kcal})$ and (d) high $(>2,350 \mathrm{kcal})$.

\section{Evaluation of physical activity}

Information on the frequency and duration of a variety of physical activities of the children was retrieved and recorded in a validated reliable questionnaire [27]. In particular, questions for this questionnaire were read by the researcher in front of children and they answered questions on how often and at which level of competitive requirement they participate in sports related physical activities such as brisk walking, running, swimming and cycling; non-sports related activities, such as going out with friends, social visits, going to the movies or theatre; and on the amount of time spent on sedentary activities (e.g., watching television, working on a computer, playing video games). The physical activity questionnaire has been previously validated in metabolic equivalence (MET, $1 \mathrm{MET}=3.5 \mathrm{ml} / \mathrm{kg} / \mathrm{min}$ ) by the Department of Sports Science, of the Democritus University of Thrace [27]. According to this questionnaire children were classified as having: very low (<2 MET/min), low (2-3 MET/min), moderate (4-5 MET/min), good (6 MET/min) and very good ( $>6 \mathrm{MET} / \mathrm{min}$ ) physical activity.

\section{Data analysis}

Continuous variables are presented as mean \pm standard deviation, and categorical variables are presented as absolute and relative frequencies. Contingency tables with the calculation of chi-square test evaluate the associations between the categorical variables. Relationships between genders and continuous variables are tested by the use of Student's t-test (for normally distributed variables), after checking for homoskedacity, or the Mann-Whitney test for skewed variables. The estimates of the relative risks of asthma symptoms are reported by calculating the odds ratios (ORs) and the corresponding 95\% confidence intervals (CIs), using multiple logistic regression analysis. The dependent outcome was the presence of asthma symptoms and independent predictors were age, sex, body weight, body mass index, physical activity status, hours of TV viewing or playing video games, and foods consumption. Significant confounders, as well as interactions are retained in the models. Deviance residuals are calculated in order to evaluate the model's goodness-of-fit. All reported probability values (p-values) are based on twosided tests and compared to a significant level of $5 \%$. STATA 6 software was used for the all calculations (STATA Corp., College Station, Texas, USA).

\section{Results}

Table 1 presents the age-sex distribution of the study sample.

Table 2 presents various socio-demographic, anthropometric and lifestyle characteristics of the children. Approximately half of the parents reported high academic education (i.e., technological studies or universities). Three out of four children reported that they have their own room, indicating moderate to good financial status. Less than $8 \%$ of children had birth weight below $2000 \mathrm{~g}$, and nearly one out of three children was breastfed for more than 3 months. Very low physical activity was reported by $16-17 \%$ of boys and girls, while $54 \%$ of boys and $46 \%$ of girls reported that they participated in moderate to vigorous physical activities during a regular week. The time spent for sports related activities during the week was approximately 4 hours, and a similar amount of time was devoted to non-sports related activities. Moreover, children reported that they spent approximately 2 hours per day watching television or playing video games. Additionally, the frequency of having breakfast was approximately 5 times per week and it is similar between boys and girls, the number of meals are approximately 3 per day, while the number of vegetables and fruits or juices consumed on a weekly basis seems adequate.

Overall lifetime prevalence for asthma symptoms was $27.6 \%$ in boys and $20.4 \%$ in girls $(\mathrm{p}=0.027)$. Table 3 illustrates the prevalence of asthma symptoms in our sample. Twenty five percent of boys and $21 \%$ of girls reported chronic rhinitis.

Multi-adjusted logistic regression analysis revealed that in boys: $5 \mathrm{~kg}$ increase of body weight increased the odds of asthma symptoms by $13 \%$ [95\% CI 1.02, 1.25], one hour of increase of TV viewing or playing videogames increased the odds of asthma by $10 \%$ [95\% CI 1.01, 1.04]. Moreover, boys with asthma symptoms are 2.2-times more likely [95\% CI 1.34, 3.54] to not participate in any physical activity than boys without any asthma-related symptoms.

Table I: Distribution of study sample by age group.

\begin{tabular}{cccc}
\hline Age (years) & Boys & Girls & Total \\
\hline 10 & 81 & 59 & 140 \\
11 & 117 & 159 & 276 \\
12 & 125 & 159 & 284 \\
Total & 323 & 377 & 700
\end{tabular}


Table 2: Socio-demographic, anthropometric and lifestyle characteristics of the participants (percentage or mean \pm SD).

\begin{tabular}{lcc}
\hline & Boys $(\mathrm{n}=323)$ & Girls $(\mathrm{n}=377)$ \\
\hline Parents with academic education & $49 \%$ & $48 \%$ \\
Number of cars per family & $1.6 \pm 0.6$ & $1.6 \pm 0.8$ \\
Children with own bedroom & $73 \%$ & $74 \%$ \\
Birth weight $<2500 \mathrm{gr}$ & $5.5 \%$ & $7.5 \%$ \\
Breast fed $>3$ months & $27 \%$ & $31 \%$ \\
Body mass index (kg/m $\left.{ }^{2}\right)$ & $20.5 \pm 3.5$ & $20.2 \pm 3.7$ \\
Overweight & $34 \%$ & $22 \%$ \\
Obese & $9.4 \%$ & $8.6 \%$ \\
Very low physical activity & $15.9 \%$ & $16.8 \%$ \\
Watching TV or playing video & $2.3 \pm 1.3$ & $2.1 \pm 1.3$ \\
games (hours/day) & & \\
Sports activities (hours/week) & $4.1 \pm 3.3$ & $3.2 \pm 2.7$ \\
Non-sports activities (hours/week) & $4.0 \pm 2.3$ & $4.3 \pm 4.3$ \\
Frequency of eating breakfast/week & $5.2 \pm 2.4$ & $5.0 \pm 2.6$ \\
Number of meals per day & $3.2 \pm 1.0$ & $3.3 \pm 1.4$ \\
Eating at school canteen & $34 \%$ & $42 \%$ \\
Eating vegetables per week & $17.6 \pm 14.7$ & $19.7 \pm 15.2$ \\
(portion(s)) & & \\
Eating fruits per week (portion(s)) & $34.4 \pm 22.4$ & $38.6 \pm 23.4$ \\
Daily drinking of fresh juices & $43 \%$ & $40 \%$ \\
Daily drinking of soft drinks & $8.6 \%$ & $6.2 \%$ \\
\hline
\end{tabular}

Body weight and TV viewing or playing with videogames were not associated with asthma symptoms in girls. Finally, girls that did not participate in any activity during a week were $63 \%$ more likely to have asthma symptoms [95\% CI 0.86, 3.11] than girls who participated in physical activities. No significant associations were observed between specific food consumption or energy intake and prevalence of asthma symptoms.

\section{Discussion}

In this paper we present the aims, design and preliminary results of an epidemiological study on asthma, increased body weight, and physical activity among schoolchildren that has been conducted in the Athens greater area, Greece (i.e., the PANACEA study). We also present the basic characteristics of children participating in the study regarding socio-demographic status, dietary and other lifestyle habits and the reporting of asthma symptoms. To the best of our knowledge this is the first epidemiological study that evaluates dietary habits and physical activity in relation to the prevalence of asthma symptoms among school-aged children in Greece.
There have been many lifestyle changes of Greek children in the last few decades that may have contributed to the increase in the prevalence of childhood asthma. It has been reported that asthma hospital admissions of children in Athens rose by $271 \%$ from 1978 to 2000 [28]. These trends are supported by another recent publication regarding the prevalence of asthma in another Greek region (i.e. the city of Patras), where prevalence of current asthma has risen among schoolchildren from 1.5\% to $6.9 \%$ over a period of 25 years, from 1978 to 2003 [22]. All these studies are in accordance with reports from the ISAAC steering committee regarding the emerging epidemic of childhood asthma throughout the world [29]; however, prevalence of asthma in Greece is ranking among the lowest worldwide [29]. This outstanding observation may be related to factors particular to this region, such as diet.

The prevalence of obesity has reached alarming levels worldwide, especially among children. Moreover, international surveys have highlighted the fact that overweight and obesity among Greek adolescents are currently a major health problem. In particular, the findings from a survey conducted in 34 countries in 2001-2002 showed that in Greece the prevalence of overweight and obesity in adolescents was $15 \%$ and $2 \%$, respectively [30]. Likewise, Lissau et al., within the framework of the Health Behaviour in School-aged Children Obesity Working Group, reported that the highest prevalence of overweight in adolescents was observed in the United States, Ireland, Greece and Portugal, among 13 countries included in the study [31]. Our findings support these previous reports since approximately 4 out of 10 schoolchildren in our survey were found to be overweigh or obese. Future analyses of the data accumulated by the PANACEA study may help to sort out some of the possible risk factors in modern living that result in obese children.

The FFQ has been found reliable in several analyses performed by our group, but has not been validated for nutrient intake. Usual dietary intake of the participants over the week preceding enrolment was assessed by using 63 detailed descriptive questions, which included various foods and beverages that are commonly consumed in Greece. Lack of significant associations between food groups intake and asthma prevalence need further atten-

Table 3: Frequency (\%) of asthma symptoms reported in boys and girls of the study

\begin{tabular}{|c|c|c|c|c|c|c|c|c|}
\hline & $\begin{array}{l}\text { Current } \\
\text { wheeze }\end{array}$ & $\begin{array}{l}\text { Ever had } \\
\text { wheeze }\end{array}$ & $\begin{array}{l}\text { Wheeze } \\
\text { disturb sleep }\end{array}$ & $\begin{array}{l}\text { Wheeze limiting } \\
\text { speech }\end{array}$ & $\begin{array}{l}\text { Exercise } \\
\text { wheeze }\end{array}$ & Night cough & $\begin{array}{l}\text { Ever had } \\
\text { asthma }\end{array}$ & $\begin{array}{c}\text { Any asthma } \\
\text { symptoms }\end{array}$ \\
\hline Boys & $29(9.0 \%)$ & 75 (25.3\%) & $3(3.8 \%)$ & $4(4.8 \%)$ & 14 (4.8\%) & 44 (14.9\%) & 43 (13.3\%) & 89 (27.6\%) \\
\hline Girls & $22(5.8 \%)$ & 65 (18.5\%) & $8(11.6 \%)$ & $4(5.48 \%)$ & $15(4.3 \%)$ & 38 (11.0\%) & $31(8.2 \%)$ & 77 (20.4\%) \\
\hline Overall & $51(7.3 \%)$ & $140(21.6 \%)$ & II (7.4\%) & $8(5.1 \%)$ & $29(4.5 \%)$ & $82(12.8 \%)$ & 74 (10.6\%) & $166(23.7 \%)$ \\
\hline
\end{tabular}


tion, since several dietary factors interact and may influence outcome with an unpredictable way. The methods used to evaluate physical activity in children and adolescents are being widely discussed, since the accurate measurement is critical for determining current levels of physical activity [32]. A number of different measurement approaches have been described for assessing children's activity, but no specific method can be identified as the best option for all studies. The selection of an appropriate instrument depends on the specific research question being addressed as well as the relative importance of accuracy versus practicality $[33,34]$. We used a self-report method, as it is considered more appropriate than objective instruments for a large epidemiological study, such as ours. The physical activity and lifestyle questionnaire employed has been validated and found to be reliable in Greek schoolchildren older than 10 years [27].

\section{Limitations}

The PANACEA study is a cross-sectional one and therefore has the inherent limitation of not being able to make causal relationships; the value of its findings lies in stating hypotheses. Moreover, a major issue in our analyses is that of reverse causality as respiratory symptoms may themselves alter activity, weight and diet. Although rather small, as compared to other studies, our sample size should be considered adequate for evaluating associations. However, it is not large enough in order to accurately reflect the prevalence of health related conditions (i.e. asthma, increased body weight and level of physical activity) in the investigated population. The high frequency of children from high socioeconomic background recruited in the study is most likely the result of participation bias; therefore, the importance of risk factors detected is limited to this population group. In addition, certain information, such as on breastfeeding, were retrieved from parents' reports, and therefore are subjects to recall bias.

\section{Conclusion}

Our findings underline the importance of asthma and increased body weight at a population level, in Greece, and urge for actions that should be taken from public health policy makers in order to prevent this condition among children. We anticipate that further analysis of the available data will provide current, novel and valuable information on the relations of dietary, lifestyle, physical activity and clinical characteristics with asthma, other allergies and obesity in Greek schoolchildren. Possible dietary and physical activity particularities -e.g. Mediterranean diet, specific sports activities- may offer important clues on the role of certain foods or exercise in the development of asthma symptoms.

\section{Competing interests}

The author(s) declare that they have no competing interests.

\section{Authors' contributions}

KNP is the principal investigator, had the concept, designed and co-authored the study; DBP is co-principal investigator, co-designed, and is the principal author of the paper; MBA participated in the design and coauthored the paper; AP and PN participated in the design of the study.

\section{Acknowledgements}

The authors would like to thank the field investigators of the "PANACEA" study: Adina Tsoutsou, Marios Papadopoulos, Martha Harisi (pediatricians), Maria Konstantinidou (dietician), Dionysia Kounadi (visiting nurse), Nika Priftis (sports science specialist) and George Antonogiorgos (physician, responsible for data management and analysis). The authors would also like to thank the schoolteachers, the children and their parents who participated in the study for their support.

\section{References}

I. National Centre for Health Statistics: Asthma Prevalence, Health Care Use and Mortality, 2002. [http://www.cdc.gov/nchs/prod ucts/pubs/pubd/hestats/asthma/asthma.htm]. on Tuesday, November 19,2006

2. Duhme H, Weiland SK, Rudolph P, Wienke A, Kramer A, Keil U: Asthma and allergies among children in West and East Germany: a comparison between Munster and Greifswald using the ISAAC phase I protocol. International Study of Asthma and Allergies in Childhood. Eur Respir J 1998, I I:840-847.

3. von Mutius $E$ : The rising trends in asthma and allergic disease. Clin Exp Allergy 1998, 28:45-49.

4. Matricardi PM: Prevalence of atopy and asthma in eastern versus Western Europe: why the difference? Ann Allergy Asthma Immunol 200I, 87:24-27.

5. Bjorksten B, Dumitrascu D, Foucard T, Khetsuriani N, Khaitov R, Leja M, Lis G, Pekkanen J, Priftanji A, Riikjarv MA: Prevalence of childhood asthma, rhinitis and eczema in Scandinavia and Eastern Europe. Eur Respir J 1998, 12:432-437.

6. Wang $\mathrm{Y}$, Lobstein T: Worldwide trends in childhood overweight and obesity. Int J Ped Obes 2006, I:II-25.

7. Jackson-Leach R, Lobstein T: Estimated burden of pediatric obesity and co-morbidities in Europe. Part I. The increase in the prevalence of child obesity in Europe is itself increasing. Int J Ped Obes 2006, I:26-32.

8. Lobstein T, Frelut M-L: Prevalence of overweight among children in Europe. Obes Rev 2003, 4:195-200.

9. Schachter LM, Peat JK, Salome CM: Asthma and atopy in overweight children. Thorax 2003, 58:1008-1010.

10. Tantisira KG, Litonjua AA, Weiss ST, Fuhlbrigge AL, Childhood Asthma Management Program Research Group: Association of body mass with pulmonary function in the Childhood Asthma Management Program (CAMP). Thorax 2003, 58:1036-104I.

II. Vignolo M, Silvestri M, Parodi A, Pistorio A, Battistini E, Rossi GA, Aicardi G: Relationship between body mass index and asthma characteristics in a group of Italian children and adolescents. J Asthma 2005, 42:185-I89.

12. Ward DS, Bar-Or O: Use of the Borg scale in exercise prescription for overweight youth. Can J Sport Sci 1990, I5:120-125.

13. Gokbel H, Atas S: Exercise-induced bronchospasm in nonasthmatic obese and nonobese boys. J Sports Med Phys Fitness 1999, 39:36I-364.

14. von Mutius E, Schwartz J, Neas LM, Dockery D, Weiss ST: Relation of body mass index to asthma and atopy in children: the National Health and Nutrition Examination Study III. Thorax 200I, 56:835-838. 
15. Chinn S, Rona RJ: Can the increase in body mass index explain the rising trend in asthma in children? Thorax 200I, 56:845-850.

16. Belamarich PF, Luder E, Kattan M, Mitchell H, Islam S, Lynn H, Crain EF: Do obese inner-city children with asthma have more symptoms than non-obese children with asthma? Pediatrics 2000, 106:|436-|44|.

17. Luder E, Melnik TA, DiMaio M: Association of being overweight with greater asthma symptoms in inner city black and Hispanic children. J Pediatr 1998, 132:699-703.

18. Pianosi PT, Davis HS: Determinants of physical fitness in children with asthma. Pediatrics 2004, I I 3(3 Pt I):e225-229.

19. Ellwood P, Asher MI, Bjorksten B, Burr M, Pearce N, Robertson CF: Diet and asthma, allergic rhinoconjunctivitis and atopic eczema symptom prevalence: an ecological analysis of the International Study of Asthma and Allergies in Childhood (ISAAC) data. ISAAC Phase One Study Group. Eur Respir J 200I, I 7:436-443.

20. Murray CS, Simpson B, Kerry G, Woodcock A, Custovic A: Dietary intake in sensitized children with recurrent wheeze and healthy controls: a nested case-control study. Allergy 2006 6I:438-442.

21. Devereux G, Seaton A: Diet as a risk factor for atopy and asthma. J Allergy Clin Immunol 2005, I I 5: I 109- I I I7.

22. Anthracopoulos MB, Liolios E, Panagiotakos DB, Triantou K, Priftis $\mathrm{KN}$ : Prevalence of asthma among schoolchildren in Patras, Greece: four questionnaire surveys during 1978-2003. Arch Dis Child 2007, 92(3):209-212.

23. Krassas GE, Tzotzas T, Tsametis C, Konstantinidis T: Prevalence and trends in overweight and obesity among children and adolescents in Thessaloniki, Greece. J Pediatr Endocrinol Metab 200I, I4(Suppl 5): I3|9-1326.

24. Papadimitriou A, Kounadi D, Konstantinidou M, Xepapadaki P, Nicolaidou P: Prevalence of obesity in elementary schoolchildren living in Northeast Attica, Greece. Obesity 2006, 14: I I I3- I I I7.

25. Cole TJ, Bellizzi MC, Flegal KM, Dietz WH: Establishing a standard definition for child overweight and obesity worldwide: international survey. $B M]$ 2000, 320: I240- 2243.

26. Weiland SK, Bjorksten B, Brunekreef B, Cookson WOC, von Mutius E, Strachan DP, the International Study of Asthma and Allergies in Childhood Phase II Study Group: Phase II of the International Study of Asthma and Allergies in Childhood (ISAAC II): rationale and methods. Eur Respir J 2004, 24:406-4I2.

27. Argiropoulou E, Michalopoulou M, Aggelousis N, Avgerinos A: Validity and reliability of physical activity measures in Greek high school age children. J Sports Sci Med 2004, 3:| 147-159.

28. Priftis K, Panagiotopoulou-Gartagani P, Tapratzi-Potamianou P, Zachariadi-Xypolita A, Sagriotis A, Saxoni-Papageorgiou P: Hospitalizations for childhood asthma in Athens, Greece, from 1978 to 2000. Pediatr Allergy Immunol 2005, 16:82-85.

29. Worldwide variation in prevalence of symptoms of asthma, allergic rhinoconjunctivitis, and atopic eczema: ISAAC. The International Study of Asthma and Allergies in Childhood (ISAAC) Steering Committee. Lancet 1998, 35 I:1225- I 232.

30. Janssen I, Katzmarzyk PT, Boyce WF, Vereecken C, Mulvihill C, Roberts C, et al.: Comparison of overweight and obesity prevalence in school -aged youth from 34 countries and their relationships with physical activity and dietary patterns. Obes Rev 2005, 6: I23-132.

31. Lissau I, Overpeck MD, Ruan JW, Due P, Holstein BE, Hediger ML Health behaviour in school-aged children obesity working group. Body mass index and overweight in adolescents in 13 European countries, Israel and the United States. Arch Pediat Adolesc Med 2004, 1 58:27-33.

32. Sirard JR, Pate RR: Physical activity assessment in children. Sports Med 200I, 3 I:439-454.

33. La Torre G, Masala D, De Vito E, Langiano E, Capelli G, Ricciardi W: Physical activity and socio-economic status collaborative group. Extra-curricular physical activity and socioeconomic status in Italian adolescents. BMC Public Health 2006, 6:22

34. Zahner L, Puder J], Roth R, Schmid M, Guldimann R, Puhse U, Knopfl M, Braun-Fahrlander C, Marti B, Kriemler S: A school-based physical activity program to improve health and fitness in children aged 6-13 years ("Kinder-Sportstudie KISS"): study design of a randomized controlled trial [ISRCTNI5360785]. BMC Public Health 2006, 6: 147.

\section{Pre-publication history}

The pre-publication history for this paper can be accessed here:

http://www.biomedcentral.com/1471-2458/7/140/pre pub
Publish with Biomed Central and every scientist can read your work free of charge

"BioMed Central will be the most significant development for disseminating the results of biomedical research in our lifetime. "

Sir Paul Nurse, Cancer Research UK

Your research papers will be:

- available free of charge to the entire biomedical community

- peer reviewed and published immediately upon acceptance

- cited in PubMed and archived on PubMed Central

- yours - you keep the copyright 